\title{
Instrumental response topographies of rats
}

\author{
JOHN H. HULL \\ Bethany College, Bethany, West Virginia 25032
}

\begin{abstract}
Experiments 1, 2, and 3 showed that food-deprived rats responding for food pellets made significantly more long-duration leverpresses than water-deprived rats responding for water drops. These experiments further showed that this difference in instrumental response topography is long-lived, and depends neither upon idiosyncrasies of the experimental chamber nor upon severity of deprivation conditions. In Experiment 4, food-deprived rats responding for food pellets made significantly more long-duration leverpresses than did either food- or water-deprived rats responding for sucrose solution. Human judges in Experiment 5 were able to correctly identify instrumental leverpress responses by rats as being for food or water based solely on previous viewings of other rats drinking water or eating food pellets. It appears that instrumental response topographies in rats vary depending principally upon the reinforcer received, and that these instrumental response topographies resemble consummatory response topographies.
\end{abstract}

Using pigeons as subjects, Brown and Jenkins (1968) described a procedure labeled "auto-shaping" which is different from typical operant discrimination procedures, and which has generated considerable theoretical interest (e.g., Bolles, 1972; Hearst \& Jenkins, 1974; Seligman, 1970; Shettleworth, 1972; Staddon \& Simmelhag, 1971). The discrete trials procedure employed by Brown and Jenkins involved periodic key illuminations which were followed immediately by grain presentation. No instrumental response was necessary for grain presentation; grain was presented regardless of what the pigeons did. Nevertheless, most pigeons began to peck the illuminated key within 50 trials. Brown and Jenkins reported a tendency of the pigeons to orient toward, approach, and finally peck the key during successive key illuminations.

Recent studies have used autoshaping procedures in comparing response topographies when food or water is the reinforcer (Jenkins, 1973; Jenkins \& Moore, 1973; Moore, 1973). The general finding has been that when a pigeon pecks a key in an autoshaping experiment using food as the reinforcer, the pigeon "eats" the key, pecking the key in the same manner that it subsequently pecks the grain. On the other hand, when the reinforcer is water, the pigeon "drinks" the key, contacting the key in the same manner that it subsequently drinks the water. An autoshaping experiment using rats as subjects (Peterson, Ackil, Frommer, \& Hearst, 1972) examined response topographies in rats given rein-

This research was submitted by the author as a dissertation in partial fulfillment of the requirements of the Doctor of Philosophy degree at Kent State University. The author gratefully acknowledges the assistance of Professor James S. Myer in the preparation of this paper. forcing brain stimulation or food contingent upon presentation of a retractable lever. They reported that rats given food upon lever presentation often bit or chewed the lever, while rats given brain stimulation showed very few such behaviors. Studies have also compared response topographies under autoshaping procedures with response topographies under procedures in which a response precludes reinforcer presentation ("negative automaintenance"). Both pigeons (Schwartz \& Williams, 1972) and rats (Stiers \& Silberberg, 1974) show longer duration responses under autoshaping than under negative automaintenance procedures.

Jenkins and Moore (1973) suggest that, because autoshaped responses resemble consummatory responses so closely, the autoshaped responses may be Pavlovian in nature. Further, they suggest the possibility that instrumental responses may also have classical conditioning components (see also Gamzu \& Williams, 1975; Hearst \& Jenkins, 1974). The purpose of the present study was to investigate this possibility by exploring the response topographies of instrumentally conditioned leverpress responses in rats which were exposed to a variety of deprivation and reinforcer conditions.

\section{EXPERIMENT 1}

Pilot work involved videotaping of instrumental leverpress responses of rats responding for either food or water in a free-operant procedure. It was noted that food-deprived rats often sniffed and occasionally bit the lever, as well as rubbing their paws on it, while water-deprived rats seldom exhibited these behaviors. It appeared that there might be some relationship between the reinforcer used and the instrumental response. To avoid using judges or 
another sort of potentially subjective rating device, it was decided to measure the number of lever contacts per reinforcer and the total duration of lever contact per reinforcer. The purpose of Experiment 1 was to use these two measures to examine response topographies of rats pressing a lever either for food or for water in a free-operant procedure.

\section{Method}

Subjects. The subjects were 12 experimentally naive, adult male albino rats obtained from the Holtzman Company. All subjects were housed individually under constant illumination.

Apparatus. One standard $23.5 \times 20.0 \times 19.0 \mathrm{~cm}$ high rodent test chamber was used on all experimental days for all rats. A $5.1-\mathrm{cm}$-wide response lever was mounted $5.1 \mathrm{~cm}$ above the cage's grid floor on one of the narrower walls of the cage. A section of cage wall, $5.1 \mathrm{~cm} \times 2.3 \mathrm{~cm}$ high, was removed from immediately above the lever to permit videotaping of leverpress responses. A downward deflection of $.3 \mathrm{~cm}$ was sufficient to close a microswitch and dispense one $45-\mathrm{mg}$ food pellet into a cup located $5.5 \mathrm{~cm}$ to the left of the lever, or a $.1-\mathrm{cc}$ drop of water into an identical cup the same distance to the right of the lever. All bars in the grid floor of the chamber were yoked, and the grid floor was electrically isolated from the lever. The leads of a drinkometer were attached to the grid floor and the lever. When a rat touched the lever, a circuit was completed, allowing recording of number of lever contacts per reinforcer and duration of lever contact per reinforcer to the nearest $.1 \mathrm{sec}$.

Procedure. Before recorded experimental sessions began, the rats were randomly divided into groups of six. One group was food-deprived, the other water-deprived. Three rats in each group were reduced to $80 \%$ of their free-feeding body weights, the other three in each group to $90 \%$ of their free-feeding weights.

Two days before recordings began, the rats in both groups remained in the experimental chamber until each had made 75 leverpresses. Food-deprived rats received one $45-\mathrm{mg}$ food pellet, water-deprived rats one .1-cc water drop, for each press. No handshaping procedure was used, in order to minimize the possible systematic bias of handshaping procedures on subsequent response topographies. Since rats often poked their heads and paws through the opening above the lever, even without prior magazine training leverpressing was self-conditioned in short periods of time (see Hull \& Myer, in press). On the day before recordings began, the rats again remained in the chamber until each had made 75 leverpresses. On the first experimental day, number of lever contacts per reinforcer was recorded, as was total duration of lever contact per reinforcer. At the end of the fifth day of recordings, deprivation conditions were reversed, percent body weights remaining the same for each rat, and on Experimental Days 6-10, the same procedure continued with reinforcers appropriate to the new deprivation conditions.

\section{Results}

A 2 by 2 repeated measures analysis of variance was used to compare groups on number of longduration contacts during Experimental Days 1-5. One second was arbitrarily chosen as the cutoff for long-duration lever contact; similar results were obtained when a cutoff of, for example, .5 or $1.5 \mathrm{sec}$ was used. The analysis showed that rats responding for food had significantly more long-duration lever contacts that rats responding for water, $F(1,8)=$ $28.71, p<.001$, with no significant direct or interactive effect of percent body weight or experimental days (see Figure 1).

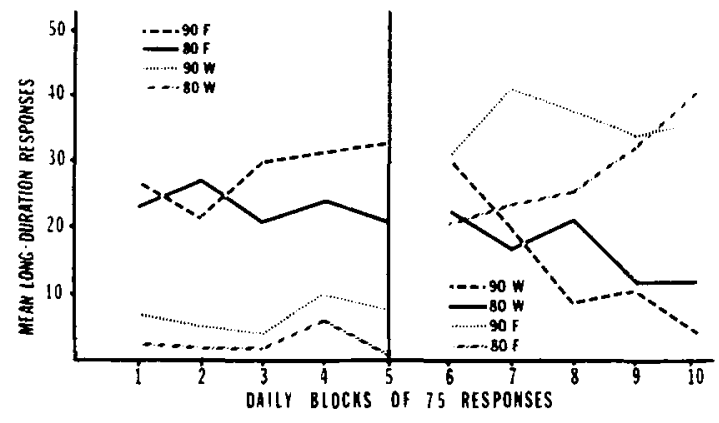

Figure 1. Mean number of long-duration (duration $\geqslant 1.0 \mathrm{sec}$ ) leverpresses as a function of daily blocks of 75 responses for food-deprived rats at $80 \%$ (80F) or $90 \%(90 \mathrm{~F})$, and water-deprived rats at $80 \%(80 \mathrm{~W})$ or $90 \%(90 \mathrm{~W})$ of their free-feeding body weights. The vertical line indicates the switch in deprivation conditions.

When deprivation conditions were reversed, a similar analysis of variance for Experimental Days 6-10 showed that the rats switched from water to food deprivation made significantly more longduration lever contacts than did rats switched from food to water deprivation, $F(1,8)=6.39, p<.05$. A significant Experimental Days by Type of Reinforcer interaction, $F(4,32)=7.95, \mathrm{p}<.001$, showed that rats switched to food deprivation immediately showed many more long-duration lever contacts, while rats switched to water deprivation reduced their number of long-duration lever contacts more slowly. Finally, there were no significant differences between groups in either block of 5 experimental days in number of lever contacts per reinforcer, the median number of lever contacts being 1 for all groups in all conditions.

\section{EXPERIMENT 2}

The first experiment demonstrated different response topographies in rats responding either for food or for water in a free-operant procedure. Further, these topographies shifted appropriately when the deprivation conditions were reversed, degree of deprivation having little effect upon response topography. However, it is possible that these differences in topography are short-lived and would disappear with repeated daily training sessions. Experiment 2 exposed groups of fooddeprived or water-deprived rats to leverpressing for food or water reinforcers, respectively, for a period of 40 days.

\section{Method}

Subjects and Apparatus. The subjects were 12 experimentally naive, adult male albino rats from Holtzman Company, housed individually under constant illumination. Before experimental sessions began, half of the rats were food-deprived and the others were water-deprived to $80 \%$ of their free-feeding body weights The apparatus was identical to that used in Experiment 1. except that both $45-\mathrm{mg}$ food pellets and .1-cc drops of water were 
dispensed into a cup located $10.2 \mathrm{~cm}$ to the right of the lever. As in the first experiment, number of lever contacts and duration of lever contact per reinforcer were recorded.

Procedure. On the first and all subsequent experimental days, rats in both groups remained in the experimental chamber until each had made 75 recorded leverpresses. Food-deprived rats received one $45-\mathrm{mg}$ food pellet, water-deprived rats one .1-cc water drop, for each press. Number of lever contacts per reinforcer and total duration of lever contact per reinforcer to the nearest $.1 \mathrm{sec}$ were recorded on each of the 40 experimental days.

\section{Results}

Figure 2 shows the mean number of lever contact per reinforcer durations greater than $.5 \mathrm{sec}$ during blocks of 5 experimental days for both food- and water-deprived groups. A repeated measures analysis of variance showed significantly more long-duration lever contacts by rats responding for food than by rats responding for water, $F(1,10)=20.26, p<.01$. There also was a significant effect of blocks of experimental days, $F(7,70)=13.08, p<.001$, and a significant Blocks of Experimental Days by Groups interaction, $F(7,70)=2.28, p<.05$. Newman-Keuls tests showed that significant differences in numbers of long-duration lever contacts were maintained across all 5-day blocks. A similar analysis of variance using number of lever contact durations $\geqslant 1.0 \mathrm{sec}$ as in Experiment 1 showed similar results, except that in Block 7 (Experimental Days 31-35) the mean difference in long-duration lever contacts did not reach an acceptable level of statistical significance $(p>.05)$. As in the first experiment, there were no significant differences between groups in number of lever contacts per reinforcer, the median number again being 1 for both groups. Mean leverpress durations were calculated every 5th day for the two groups during this second experiment. Mean leverpress duration for water-deprived rats dropped from a high of about $.20 \mathrm{sec}$ (Day 5) to a mean of about $.13 \mathrm{sec}$ for Days 25, 30, 35, and 40. Mean leverpress duration for food-deprived rats was highest on Day $10(.47 \mathrm{sec})$, and stabilized at about $.30 \mathrm{sec}$ for Days $25,30,35$, and 40 .

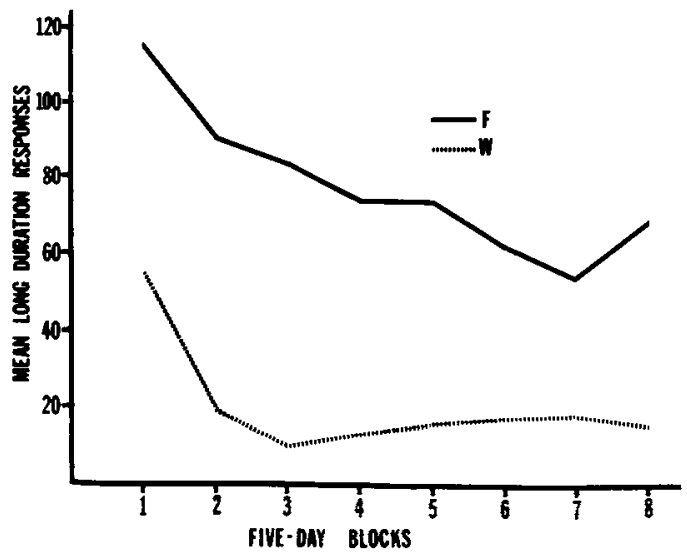

Figure 2. Mean long-duration (duration $>.5 \mathrm{sec}$ ) leverpresses as a function of 5-day blocks of responses for food-deprived $(F)$ and water-deprived $(W)$ rats.

\section{EXPERIMENT 3}

Experiment 2 showed that the differences in response topographies of rats responding for food or water were quite durable, and that such differences do not simply reflect a difference in number of lever contacts per reinforcer. However, it is possible that some idiosyncrasy of the experimental apparatusperhaps distance from the lever to the reinforcer dispenser-might be responsible for the differences in topographies. Experiment 3 varied the distance between the lever and the dispenser, as well as the type of movement needed to get to the dispenser, and measured the effects of these variables on response topographies.

\section{Method}

Subjects and Apparatus. The subjects were six experimentally naive, adult male albino rats from the Holtzman Company, housed individually under constant illumination. Half of the rats were water-deprived, half food-deprived, to $80 \%$ of their free-feeding body weights. The apparatus was identical to that used in Experiment 1. On all experimental days, number of lever contacts per reinforcer and duration of lever contact per reinforcer to the nearest $.1 \mathrm{sec}$ were recorded.

Procedure. On all experimental days, each rat remained in the experimental chamber until it had made 75 recorded leverpresses. During Days 1-3, the "short-box" phase, reinforcers were dispensed into a cup $5.5 \mathrm{~cm}$ to the right of the response lever. On Days 4-7, the "long-box" phase, reinforcers were dispensed into a cup on the side of the box opposite the lever, at a distance of $17 \mathrm{~cm}$ from the lever. For all responses, all rats received reinforcers appropriate to their deprivation conditions: $45-\mathrm{mg}$ food pellets for food-deprived rats, .1-cc water drops for waterdeprived rats.

\section{Results}

Figure 3 shows the mean number of long-duration (duration $\geqslant 1.0 \mathrm{sec}$ ) leverpresses during the 3 days of the short-box phase and the 4 days of the long-box phase. A repeated measures analysis of variance for the short-box phase showed that food-deprived rats had significantly more long-duration lever contacts than did water-deprived rats, $F(1,4)=26.45$, $\mathrm{p}<.01$. The analysis further showed a significant effect of experimental days, $F(2,8)=21.41, p<.001$, and a significant Days by Groups interaction, $F(2,8)$ $=4.56, \mathrm{p}<.05$. A similar analysis of variance for the long-box phase also showed a significant group effect, $F(1,4)=48.87, p<.01$, and experimental days effect, $F(3,12)=5.73, p<.05$, but no significant interaction of groups and days. Both groups showed some rise in mean number of long-duration leverpresses on the first day of responding in the long-box phase, but both groups rapidly returned to levels of responding reached in the short-box phase. As in Experiments 1 and 2, there were no significant differences in number of lever contacts per reinforcer in either phase. 


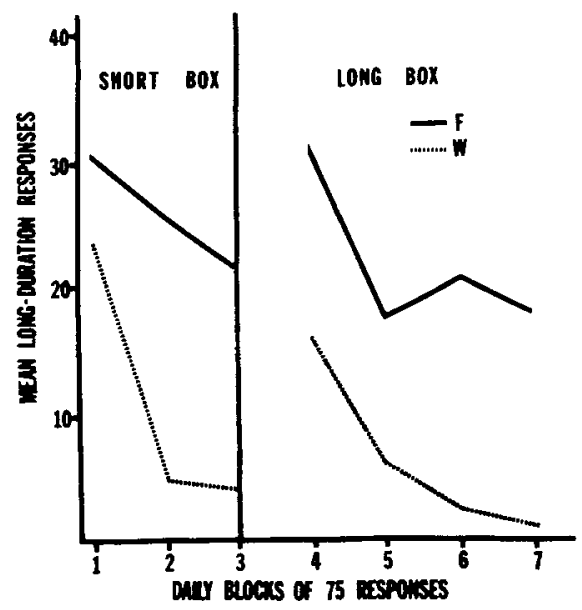

Figure 3. Mean long-duration (duration $\geqslant 1.0 \mathrm{sec}$ ) leverpresses as a function of daily blocks of $\mathbf{7 5}$ responses for food-deprived (F) and water-deprived (W) rats in both the short-and long-box phases of Experiment 3.

\section{EXPERIMENT 4}

The previous experiments demonstrated that the topographies of instrumental responses in food- and water-deprived rats do not change substantially over time or reflect some obvious idiosyncrasy of the experimental apparatus. However, it is still possible to maintain that differences in response topographies reflect differences in deprivation conditions, not differences in the reinforcers used. If instrumental response topography depends primarily upon the type of deprivation used, then groups of fooddeprived animals should have similar response topographies, regardless of the type of reinforcer used. On the other hand, if the response topography depends primarily upon the type of reinforcer used, food-deprived rats given liquid reinforcers-for example, drops of sucrose solution-should have response topographies different from those given food pellets, but no different from those of waterdeprived rats also given drops of sucrose solution.

\section{Method}

Subjects and Apparatus. The subjects were 24 experimentally naive, adult male albino rats from the Holtzman Company, housed individually under constant illumination. Half were fooddeprived, half water-deprived, to $80 \%$ of their free-feeding body weights. The apparatus was identical to that used in Experiment 2.

Procedure. On all 7 experimental days, each rat remained in the experimental chamber until it had made 75 recorded leverpresses. Half of the food-deprived rats received one $45-\mathrm{mg}$ food pellet for each press, half of the water-deprived rats one $.1-\mathrm{cc}$ water drop. The other half of the animals in both groups received one .1 -cc drop of $20 \%$ (by weight) sucrose solution per press. On all experimental days, lever contact per reinforcer duration to the nearest 1 sec was recorded.

\section{Results}

Figure 4 shows the mean numbers of longduration (duration $\geqslant 1.0 \mathrm{sec}$ ) lever contacts for the four groups across the 7 experimental days. A repeated measure analysis of variance showed significant effects of experimental group, $F(3,20)=9.09$, $p<.001$, and experimental days, $F(6,120)=60.76$, $\mathrm{p}<.001$, but no significant Groups by Days interaction. Newman-Keuls tests indicated that the fooddeprived group receiving food pellets made significantly more long-duration lever contacts than any of the other three groups, and that food-deprived rats receiving sucrose solution made significantly more long-duration lever contacts than did water-deprived rats responding for water. The water-deprived group receiving sucrose solution did not differ significantly from the food-deprived group responding for sucrose solution, nor did they make significantly more longduration lever contacts than did the water-deprived group responding for water.

\section{EXPERIMENT 5}

Experiment 4 demonstrated that instrumental response topographies depend primarily upon the type of reinforcer used, not the deprivational state. However, to parallel more closely the autoshaping research, it must further be shown that the instrumental response resembles the consummatory response. In Experiment 5, human observers viewed rats that were eating food pellets or drinking water, then watched videotapes of instrumental leverpress responses by rats and were asked to judge whether the videotaped segments showed rats responding for food or for water.

\section{Method}

Subjects and Apparatus. The subjects were four experimentally naive, adult male Long-Evans rats from Huntingdon Farms,

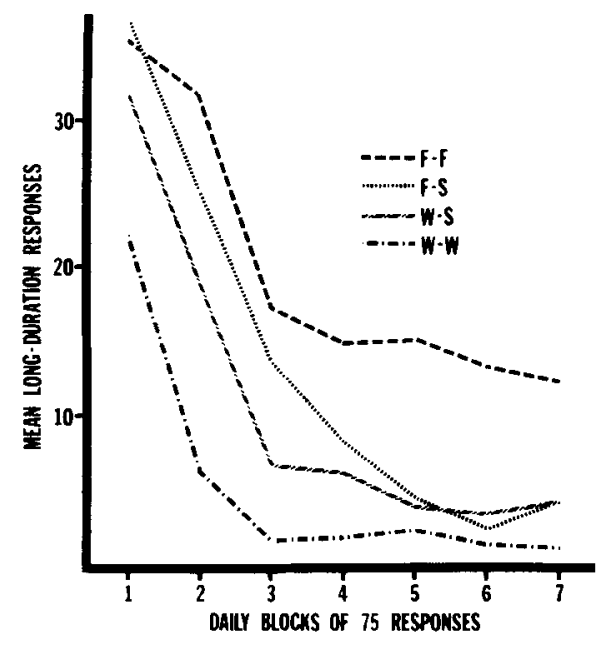

Figure 4. Mean long-duration (duration $\geqslant 1.0 \mathrm{sec}$ ) leverpresses as a function of daily blocks of 75 trials for food-deprived rats given either food pellets (F-F) or sucrose solution (F-S), or waterdeprived rats given either water (W-W) or sucrose solution (W-S) for each leverpress. 
and four experimentally naive, adult male albino rats from the Holtzman Company. Half of the rats from each supplier were food-deprived, half water-deprived, to $80 \%$ of their free-feeding body weights. The apparatus used to train the rats was identical to that used in Experiments 2 and 4. Observers were six Kent State University graduate students, none of whom had prior knowledge of the purpose of the experiment.

Procedure. All Long-Evans rats were initially trained to press the lever in the same manner as in the previous experiments, each rat making 75 recorded leverpresses during sessions on 2 consecutive days. Food-deprived rats received one $45-\mathrm{mg}$ food pellet for each press, water-deprived rats one .1-cc water drop. On the third day, front-view videotapes were made of each rat's leverpresses through the $5.1 \times 2.3 \mathrm{~cm}$ high opening just above the lever in the cage wall. The videotapes showed the rats' approaches toward and contacts of the lever, but did not show the consummatory responses. No sound recordings were included with the videotapings. Following the training and videotaping of the Long-Evans rats, the albino rats received identical training for 2 days.

While the albino rats were responding during sessions on the third day, they were watched by the six human observers. Each observer was alone when observations were made. Each observer was first told that it might be possible to determine whether a rat was pressing a lever for food or for water simply by watching how other rats ate food pellets or drank water. The observers then watched the albino rats eating food pellets or drinking water in the experimental chamber, without seeing the instrumental leverpresses. Finally, each observer viewed videotaped leverpress responses of the Long-Evans rats pressing either for food or for water. Each viewed 12 randomly arranged $10-15$ sec sequences; each Long-Evans rat appeared in three sequences. At no time did the videotapes show the consummatory responses. After each sequence was shown, the observer was asked to write down whether the rat was pressing the lever for food or for water. After all 12 sequences were shown, each observer was asked to write down what criteria were used in making judgments.

\section{Resuits}

All observers correctly identified 10 or more of the 12 sequences as being views of rats pressing either for food or for water. Four observers made no errors; the other two observers made one and two errors, respectively. When asked about what criteria they based their decisions on, the observers commonly mentioned behaviors such as sniffing and pawing the lever by rats responding for food, and described the responding by rats receiving water as swift and mechanical. Thus, based solely upon viewing rats eating food pellets or drinking water drops, human observers were able to decide accurately whether videotapes of rats' leverpress responses showed the rats responding for food or for water.

\section{GENERAL DISCUSSION}

Experiment 1 of the present study demonstrated different response topographies by rats pressing a lever either for food or for water in an instrumental conditioning procedure, a difference which had previously been demonstrated in studies of autoshaped keypecking by pigeons (Jenkins \& Moore, 1973) and autoshaped lever contacts by rats (Peterson et al., 1972). Experiments 2 and 3 showed that these differences are long-lived, and do not depend upon idiosyncrasies of the experimental chamber. Experiment 4 showed that the type of reinforcer used is related to response topography, regardless of deprivation condition; food-deprived rats pressing a lever for food pellets made significantly more longduration leverpresses than did either food- or waterdeprived rats pressing for sucrose solution. Finally, Experiment 5 showed that differences in instrumental response topographies are related to differences in consummatory response topographies. Based solely upon viewing rats eating food pellets and drinking water drops, human observers subsequently were able to correctly identify instrumental leverpresses as being made either for food or for water.

The relationship of instrumentally conditioned responses to consummatory responses seems puzzling at first. One might expect some sort of "stimulus substitution"-that is, the source of the signal for trial onset coming to serve as a surrogate for the reinforcer (Hearst \& Jenkins, 1974; Jenkins \& Moore, 1973) - to occur in autoshaping experiments, where stimulus-reinforcer relations are essentially Pavlovian. According to orthodox instrumental conditioning theory, however, an organism learns some "arbitrary operant" to receive reinforcers. Since all initial responses by all rats in the present study were the results of subjects poking their heads or paws through the opening above the lever, one would expect all subsequent response topographies to be similar, regardless of the reinforcers used. The present study shows that this is not the case. The present study indicates that the lever in traditional instrumental conditioning studies may become a reinforcer surrogate; rats responded to the lever in the same way they subsequently responded to the reinforcer.

The mean lever contact durations reported for rats responding for food pellets in the present study are much longer than the lever contact durations reported by Stiers and Silberberg (1974) for rats in an autoshaping procedure. However, the mean lever contact durations of the two studies are not directly comparable. First, Stiers and Silberberg recorded the duration of only the first lever contact on each trial; the present study measured total contact duration per reinforcer, regardless of number of contacts. Second, the rats in the present study were required not only to contact the lever but to press the lever enough to activate a microswitch; Stiers and Silberberg recorded only lever contacts as responses, without requiring a leverpress.

There are several important points the present study does not address. For example, do response topography differences persist on various reinforcement schedules? Do they occur during discrimination training? Future research will explore these 
questions, and will attempt to assess the theoretical importance of these differences in response topography.

\section{REFERENCES}

Bolles, R. C. Reinforcement, expectancy, and learning. Psychological Review, 1972, 79, 394-409.

Brown, P. L. \& JENkINS, H. M. Auto-shaping of the pigeon's key peck. Joumal of the Experimental Analysis of Behavior, 1968, 11, 1-8.

GAmzU, E., \& Williams, D. R. The source of keypecking in autoshaping. Animal Learning \& Behavior, 1975, 3, 37-42.

HeARST, E.. \& Jenkins, H. M. Sign-tracking: The stimulusreinforcer relation and directed action. Austin: Psychonomic Society, 1974.

Hull, J. H., \& MYER, J. S. Rapid self-shaping of lever pressing by rats. Journal of General Psychology, in press.

JENKINS, H. M. Effects of the stimulus-reinforcer relation on selected and unselected responses. In R. A. Hinde \& J. S. Hinde (Eds.), Constraints on learning. New York: Academic Press, 1973.

Jenkins, H. M., \& Moore, B. R. The form of the auto-shaped response with food and water reinforcements. Journal of the Experimental Analysis of Behavior, 1973, 20, 163-181.

MOORE, B. R. The role of directed Pavlovian reactions in simple instrumental learning in the pigeon. In R. A. Hinde \& J. S. Hinde (Eds.), Constraints on learning. New York: Academic Press, 1973.

Peterson, G. B., Ackil, J. E., Frommer, G. P., \& Hearst, E. S. Conditioned approach and contact behavior toward signals for food or brain stimulation reinforcement. Science, 1972, 177, 1009-1011.

Schwartz, B., \& Williams, D. R. Two different kinds of key peck in the pigeon: Some properties of responses maintained by negative and positive response-reinforcer contingencies. Journal of the Experimental Analysis of Behavior, 1972, 18, 201-216.

Seligman, M. E. P. On the generality of the laws of learning. Psychological Review, 1970, 77, 406-418.

ShETtLewORTH, S. J. Constraints on learning. In D. S. Lehrman, R. A. Hinde. \& E. Shaw (Eds.), Advances in the study of behavior. New York: Academic Press, 1972.

Staddon, J. E. R., \& Simmelhag, V. L. The "superstition" experiment: A reexamination of its implications for the principles of adaptive behavior. Psychological Review, 1971, 78, 3-43.

Stiers, M., \& Silberberg, A. Lever-contact responses in rats: Automaintenance with and without a negative responsereinforcer dependency. Journal of the Experimental Analysis of Behavior, 1974, 22, 497-506.

(Received for publication December 6. 1976; revision accepted March 2, 1977.) 